\title{
The Study of Adipose Derived Mesenchymal Stem Cells Mixed with Platelet Rich Fibrin Matrix in Augmentation and Rejuvenation of The Lower Leg: A Comparative Study
}

\author{
NAHED SAMIR BOUGHDADI, M.D. \\ The Department of Plastic and Reconstructive Surgery, Faculty of Medicine, Ain Shams University, Cairo, Egypt
}

\begin{abstract}
Background: Adipose tissue is an abundant source of mesenchymal stem cells. The use of transplantation of preadipocytes and adipocytes to restore the volume of tissues has added a lot to the value of fat transplantation strategies. These cells are more advantageous as a cell source than mature adipocytes. They are capable of both proliferating to obtain larger cell numbers and of differentiating to obtain the tissue of interest. This study aims to compare the results of traditional fat injection and activated adipose derived mesenchymal stem cells injection enriched with platelet rich fibrin matrix in augmentation and rejuvenation of the distal leg.
\end{abstract}

Patients and Methods: The study was conducted on 14 patients who had fat injection of the leg. They were divided into 2 groups: 7 cases by traditional fat injection and 7 cases by injection of (PRFM) with the adipose derived mesenchymal stem cells. Post-operative assessment at 3, 6, 18 months were done subjectively. Patients in group 11 were subjected to monthly injection of platelet rich plasma. The final results in each patient were evaluated according to the comparison of pre-and post-operative photos and measurements of circumference for the degree of improvement by the patients. Three populations including the patient herself, a surgeon not involved in the procedure and nurse were subjected to standardized questionnaire.

Results: All patients were treated bilaterally, they knoticed that the use of fat grafting not only provided a volumetric effect but also improved the quality of skin. They felt their skin is thicker, firmer with less wrinkles and pigmentation and less need for moisturizers.

Conclusion: Mixing fat containing activated mesenchymal stem cells with platelet rich fibrin matrix gave better long lasting results than traditional fat injection as regarding both volume and skin quality.

Key Words: Autologous fat graft - Adipose derived mesenchymal stem cell - Platelet rich fibrin matrix Platelet rich plasma - Leg rejuvenation.

\section{INTRODUCTION}

There is an increasing demand for leg contouring and improving its deformities nowadays, so it became advantageous to use fat transfer for this purpose. Autologous fat transfer is a frequently used technique in aesthetic surgeries which restore natural youthful look and beauty. It can replace the loss of subcutaneous tissue and correct many cosmetic deformities such as skin atrophy and deep wrinkles [1].

Early experience noticed that fat graft reabsorption was the main drawback; with $50-90 \%$ graft loss [2-4]. To prevent fat graft resorption, several techniques have been described [1]. Many authors proposed that the reason for fat resorption is the lack of sufficient revascularization of the central part of the fat graft [5-8]. To overcome this problem, many studies suggested that the use of "Atraumatic Harvesting" with low negative pressure with small volume and "Layered Implantation" in different planes for each placement, may improve the survival rates of transplanted fat $[\mathbf{9 , 1 3}]$.

Several researches regarding specimen handling, type of cannula, the donor site, and anatomic characteristics of patients noticed that all these factors affect the degree of resorption of the transplanted fat graft [10-12]. Boschert et al., in 2002, analyzed whether adipocyte viability varied between the top, middle and bottom layers of the centrifuged aspirates. After centrifugation; they found that cells in the bottom-most layer contained 250 times more viable adipocytes compared to fat in the top layer, and 150 times more viable cells than fat in the middle layer [14].

The presence of Adipose Derived Mesenchymal Stem Cells (ADMSCs) within the transferred fat is very crucial. Mesenchymal stem cells are abundant in adipose tissue and provide several benefits. 
Their presence improve angiogenesis, graft vascularity [17] and contribute actively to the adipocyte pool allowing fat grafts to maintain their volume. These types of cells can be concentrated by centrifugation of the harvested fat $[\mathbf{1 7 , 1 8}]$ resulting in an increased their number per milliliter in transplanted fat [19].

There are several studies about the ability of platelet rich plasma to augment bone growth, promote wound healing and improve survival of fat grafts as because of its content of high concentration of various growth factors and other bioactive proteins that improve tissue repair and regeneration processes [20-22]. Results of clinical trials have suggested that growth factors in PRP not only influence the viability of transferred fat cells but may also play a bioactive role in the differentiation of precursor adipocytes within the graft into their mature form [23-26]. These clinical studies have stated the efficacy and safety of use of PRP in hard-and soft-tissue augmentation by stimulating and enhancing native repair and regeneration [27-31].

Platelet rich fibrin matrix is clinically documented as better product than platelet rich plasma due to its fibrin content. It can stimulate the production of viable blood vessels, fat cells, and collagen deposits that seem to persist over time. PRFM differs from other PRP systems in that it promotes the physiologic functions of fibrin and avoids the potential drawbacks of the included leukocytes. PRFM relies on local tissues' ability to generate a cellular response, and may not be as effective in unfavorable wound conditions such as hypoxia or infection [32-34].

Fibrin matrix is essential for wound response, which enhances the delivery of growth factors. Fibrin mediates the adhesion of fibroblasts and other cells to the injured site. Basic Fibroblast Growth Factor (bFGF) also has a high binding affinity specifically for fibrin and fibrinogen. Studies have shown enhanced survival and differentiation of transplanted preadipocytes when coinjected with fibrin as a carrier material compared with controls. Other clinical studies have reported good results when treating patients with autologous fat co-injected with PRFM [35-40].

\section{Aim of the work:}

This study aims to assess the use of Platelet Rich fibrin matrix as a promoter for Adipose derived mesenchymal stem cells through their mixture to enhance graft taking and increasing the survival rates of the transferred fat in comparison to fat injection alone.

\section{PATIENTS AND METHODS}

The study was conducted between 2014 and 2016, included 14 patients. All were females; with age ranging from 40 to 55 years. Body mass index ranged from (19-22.9). Patients complained from thin deformed lower legs with prominent bones and Achilles tendon) in addition to aging skin signs including wrinkles, pigmentations and irregularities and all underwent autologous fat grafting for leg augmentation and rejuvenation. Amount of fat injection was 100-200cc in lower third of the leg from the tendoachillies prominence to the point of maximum protrusion of calf muscles. Some patients demanded extra injection of fat for calf protrusion and some to improve ireegularities in the zone distal and around patellar protrusion.

The patients were divided randomly into two groups based on the addition of Platelet Rich Fibrin Matrix (PRFM) to the fat graft as a promoter or not:

- Group (I) included 7 patients who underwent fat transfer without adding PRFM.

- Group (II) included 7 patients who underwent fat transfer after adding PRFM.

Pre-operative evaluation: Each patient is first photographed with the defects to be treated. The distal third of the leg is marked by drawing line horizontally from medial to lateral malleoli. Drawing horizontal line surrounding the most prominent point of calf muscles a vertical line is drawn from the most prominent point of calf muscle to tendoachilies in order to divide this region into two halves medial and lateral halves in order to inject equally both halves unless assymetrical. The amount of injection is $100-200 \mathrm{cc}$ per leg, means $50-100 \mathrm{cc}$ for each half.

Technique of fat transfer: The entire procedure took 60-90 minutes and was performed under either local anesthesia or spinal anesthesia.

\section{I- The technique of fat harvesting [41]:}

- The lower abdomen in each patient was chosen as the donor site for fat graft harvesting.

- The tumescent solution, containing $0.08 \%$ lidocaine and 1:500,000 of epinephrine, was infiltrated into the donor site.

- A $3 \mathrm{~mm}$ liposuction cannula was connected with a $60 \mathrm{ml}$ syringe for fat graft harvesting. 
- An appropriate amount of fat was gently aspirated to be prepared first before injection.

\section{II- Preparation of Platelet Rich Fibrin Matrix (PRFM) [42]:}

- A vacuum collection tube containing a thixotropic separator gel is prepared for blood collection. This tube is centrifuged for 6 minutes at 1100rpm, which yields a supernatant plasma/platelet suspension and the cellular components (erythrocytes and leukocytes) below the separator gel. The plasma/platelet suspension is transferred to a second vacuum tube containing calcium chloride, which initiates the polymerization of fibrin. This polymerization process is completed in about 10 to 12 minutes. These platelets are, embedded in the fibrin matrix, and differ as mentioned before of its capababilites of sustained release of growth factors for longer time.

\section{I- Refining and purification of fat:}

- To remove lidocaine, oil, and residual red blood cells the fat grafts were washed with normal saline inside the syringe in sterilized condition and then were centrifugated at low speed (1000 rpm, for 2 minutes).

- After centrifugation, the fat cells was concentrated in the middle layer; this concentrated fat underwent second centrifugation. So, it was divided into 3 parts top, middle and bottom. I used the cells from the bottom fat layer of centrifuged aspirates which have a large number of viable cells.

- However, in group II, double dose of fat mixed with half dose of PRFM before injection, the temperature is controlled at $25^{\circ} \mathrm{C}$ throughout the procedure.

\section{II- The technique of fat injection:}

- In the two groups, incision was made in skin creases over calcaneal area and fat grafts were injected with a syringe connected to a blunt cannula whose external diameter was 2 or $3 \mathrm{~mm}$.

- Injection was done in the subcutaneous plane in previously demarcated area.

On both sides of the Achilles tendon in a retrograde manner 50-100cc on both sides of the vertically drawn line, dispersing small a liquots of fat (0.3-0.5ml per pass).

- Gentle massage was done with fingers and palms of the surgeon to ensure a smoothly distributed correction.

\section{III- Post-operative care and follow-up:}

- The grafted site was immobilized with venous compression stocking for 3 weeks.

- Post-operative antibiotic was recommended for all cases for 10 days.

- Patients were instructed to raise their legs during sitting and to avoid long periods of standing.

Post-operative assessment took place after 3, 618 months by measuring the circumference at the mid-point of the lower one third of leg according to previous description. Standard photos were taken during each visit. These photos were used to compare both the shape and the skin condition as regarding wrinkles, texture, pigmentations in the injected site with those taken pre-operatively.

\section{Follow-up visits for group II:}

Cases of group II were subjected to platelet rich plasma injection on monthly basis for 6 months, this aims to improve skin quality and also refine hyper-pigmentations and wrinkles, this procedure was done as out-patient clinic.

\section{Technique of platelet rich plasma preparation:}

- A tube containing an anticoagulant (citrate dextrose) is prepared to collect (10cc of blood). The first centrifugation "soft centrifugation" is done at speed of (3600rpm for 3 minutes), which allows blood separation into three layers, namely bottommost RBC layer (55\% of total volume), top most acellular plasma layer called Platelet Poor Plasma (PPP) (40\% of total volume), and an intermediate Platelet Rich Plasma (PRP) layer (5\% of total volume) called the "buffy coat".

- This tube underwent a second centrifugation (2400rpm for 15 minutes), called "hard centrifuge". This allowed the platelets (PRP) to settle at the bottom of the tube with a very few RBCs. The acellular plasma, PPP ( $80 \%$ of the volume), was found at the top. Most of the PPP was removed with a syringe, and the remaining PRP was injected on each visit. We can use PPP for topical application also [43].

The final results in each patient were evaluated subjectively according to sets of pre-and postoperative photos by the patients themselves, a plastic surgeons staff not involved in the procedure, and nurse in out patient clinic. The three populations performed standardized questionnaire and evaluated pre and post-operative photos at 3, 6, 18 months. Participants were also asked to evaluate improvement in contour and persistence of results on an 
analog scale [score: Poor results $=0$, satisfactory results $=1$, excellent results $=2]$.

\section{RESULTS}

In all patients of both groups, the lower abdomen was used as a donor site for fat. The amount of fat that lipo-aspirated ranged from 100 to $200 \mathrm{cc}$. Technique of harvesting, handling and injection of fat containing mesenchymal derived fat cells was fixed. In group II fat was mixed with platelet rich fibrin matrix in ratio of $2: 1$ before injected by same technique as group I. The follow-up visits continued till 15.1+3 months.

All patients noticed that the use of fat grafting not only provides a volumetric effect but also improves the quality of skin. They feel their skin is thicker, firmer with improved contour. These findings were higher in group II.

Objective evaluation of results was also done including pre and post-operative measurements of lower leg circumference at the previously mentioned site and those measurement were recorded for both groups. Timing of measurements was before the procedure and at 3,6 and 18 months (Tables 1,2).

In group I one case required repetition of injection after 18 month and the ratio of fat loss ranged from $28 \%$ to $50 \%$ after 18 months. In group II the loss percent reached up to $28.5 \%$ after 18 months.

As regard the post-operative complications (Table 3), all the patients of both group had edema and bruising, those resolved within 7 to 10 days. Three cases ( 2 in group I, 1 in group II) had dark discoloration of the skin which lasted 2 months in group I while resolved early in group II. 5 cases (3 in group I, 2 in group II) had mild numbness of the incision site which resolved in three weeks but there was no case of nerve injury. No recorded infection or cellulitis in both groups.

Neither scars, nor obvious contour irregularities were visible in any patient during the follow-up. No further complications were demonstrated during the long-term follow-up.

The means of scoring system during all followup visits of each case that was assessed by the patients, independent plastic surgeons, and nurse and the average of each population score were summarized in (Table 4).
Table (1): Patient demographic data for group I: Autologous fat grafting without any additions.

\begin{tabular}{lccccccc}
\hline Case number & 1 & 2 & 3 & 4 & 5 & 6 & 7 \\
\hline Age, years & 40 & 50 & 48 & 47 & 55 & 45 & 41 \\
Circumference, in cms: & & & & & & & \\
$\quad$ Pre-operative & 17 & 19 & 20 & 20 & 21 & 18 & 19 \\
3 month & 22 & 26 & 27 & 28 & 28 & 24 & 23 \\
6 months & 21 & 25 & 26 & 23 & 26 & 22 & 22 \\
18 month & 20 & 24 & 24 & 20 & 26 & 21 & 21 \\
\hline
\end{tabular}

Table (2): Patient demographic data for group II: Autologous fat grafting with adding activated PRFM.

\begin{tabular}{lccccccc}
\hline Case number & 1 & 2 & 3 & 4 & 5 & 6 & 7 \\
\hline Age, years & 50 & 48 & 43 & 47 & 43 & 41 & 48 \\
Circumference, in cms: & & & & & & & \\
$\quad$ Pre-operative & 19 & 21 & 19 & 18 & 22 & 20 & 19 \\
3 month & 24 & 27 & 23 & 25 & 28 & 24 & 23 \\
6 months & 23 & 26 & 22 & 23 & 26 & 24 & 23 \\
18 month & 23 & 25 & 22 & 23 & 26 & 24 & 23 \\
\hline
\end{tabular}

Table (3): Number of cases with complications.

\begin{tabular}{lcc}
\hline & Group I & Group II \\
\hline Edema and bruising & 7 & 7 \\
Dark discoloration & 2 & 1 \\
Numbness of incision site & 3 & 2 \\
Infection & - & - \\
\hline
\end{tabular}

Table (4): Means of patients, doctors and nurse scoring for each patient.

\begin{tabular}{lccccccc}
\hline \multirow{2}{*}{$\begin{array}{l}\text { Case } \\
\text { No. }\end{array}$} & \multicolumn{3}{c}{ Group I } & & \multicolumn{3}{c}{ Group II } \\
\cline { 2 - 4 } \cline { 5 - 7 } & Patients & Doctors & Nurses & Patients & Doctors & Nurses \\
\hline 1 & 1 & 1 & 2 & & 1 & 1 & 2 \\
2 & 1 & 1 & 1 & & 2 & 2 & 2 \\
3 & 0 & 0 & 1 & & 1 & 2 & 1 \\
4 & 2 & 1 & 2 & & 2 & 1 & 2 \\
5 & 1 & 1 & 1 & & 2 & 2 & 2 \\
6 & 0 & 0 & 0 & & 1 & 1 & 3 \\
7 & 2 & 1 & 2 & & 1 & 2 & 1 \\
Average & 1.0 & 0.7 & 1.3 & 1.4 & 1.6 & 1.7 \\
\hline
\end{tabular}



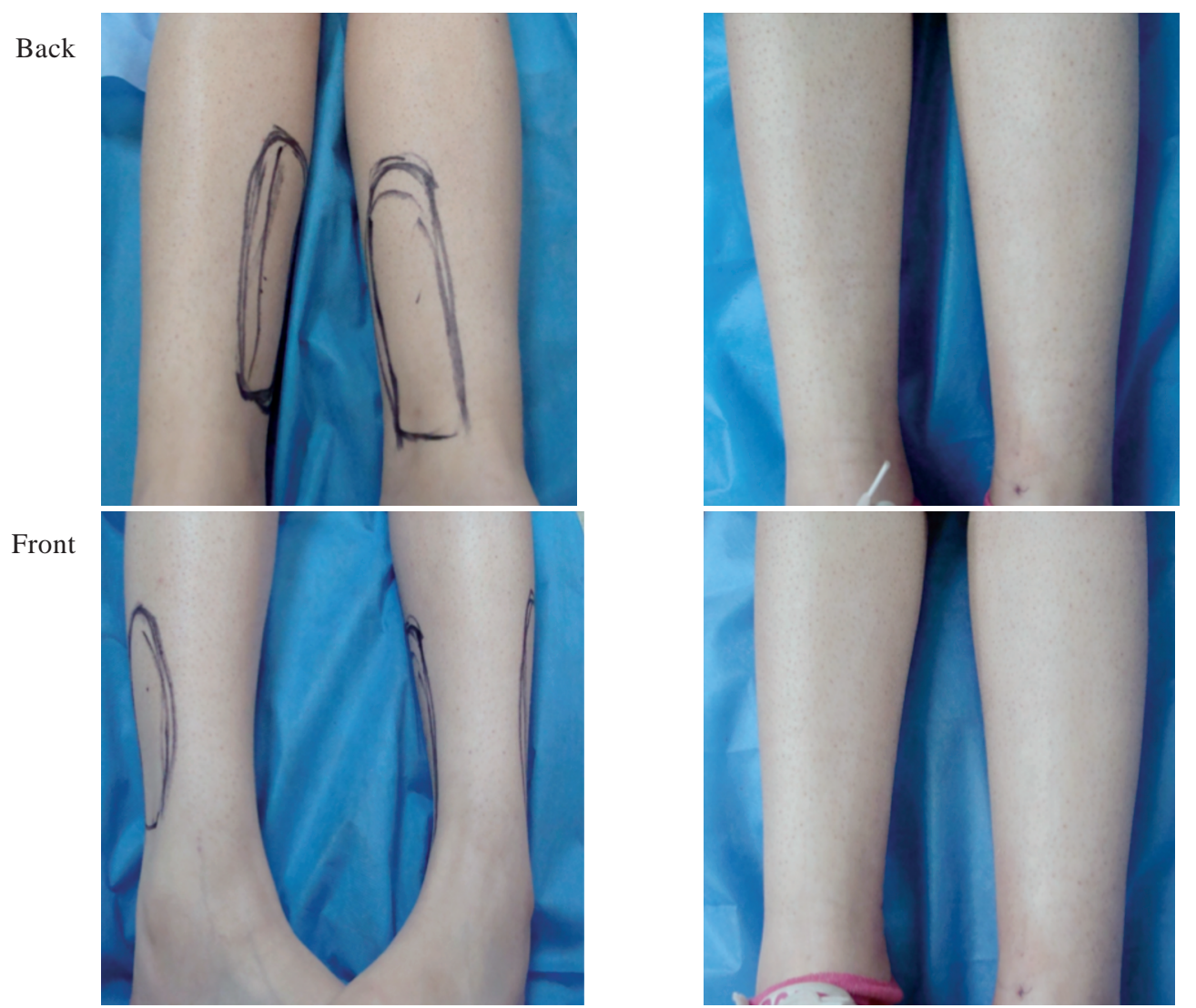

Fig. (1): A case of Group I: Who underwent fat transfer without adding PRP, clinical photography of preoperative and 6 months after fat transfer.
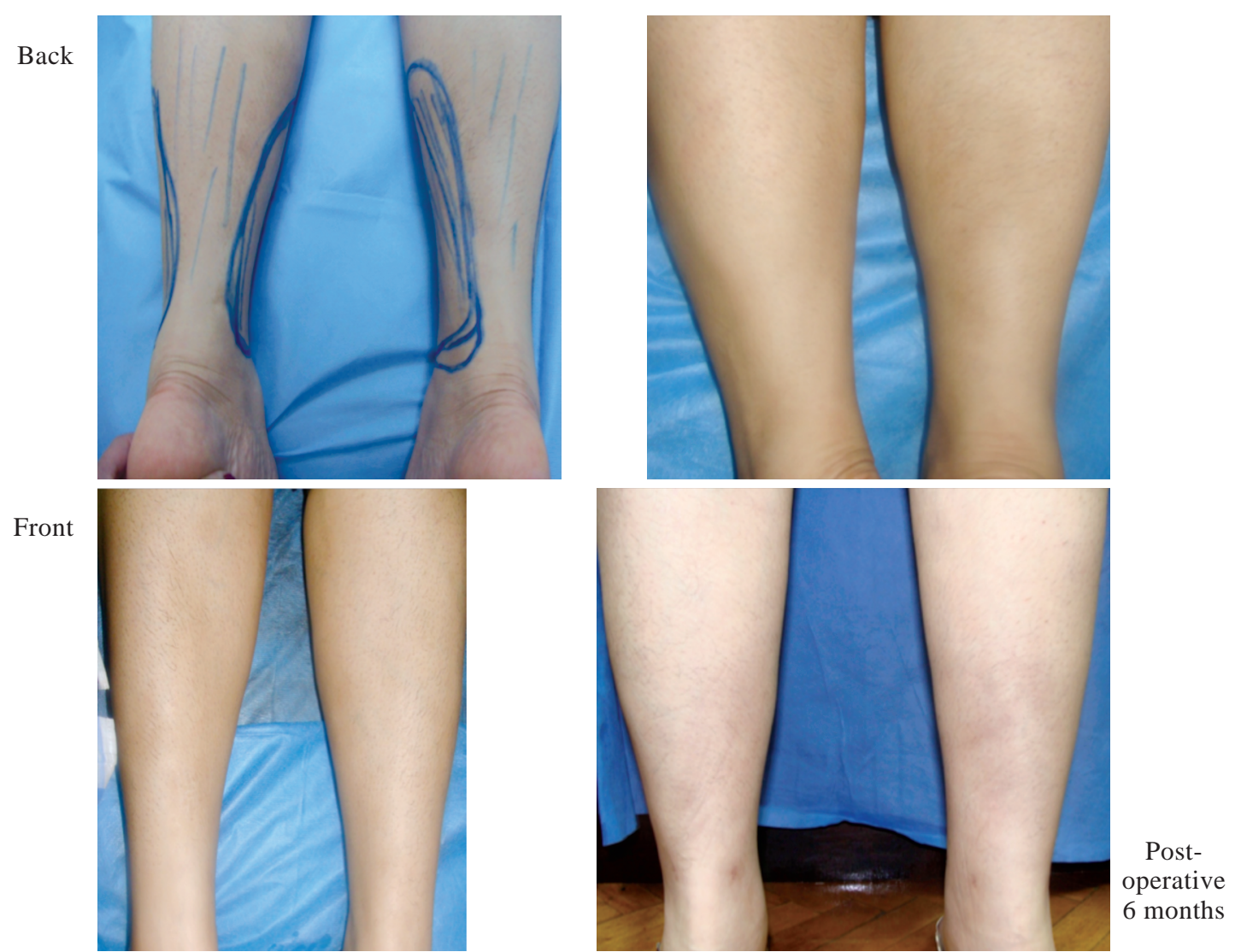

Fig. (2): Group II case of pre-operative and post-operative after fat injection with 6 months combined with PRFM and follow-up monthly with PRP. 


\section{DISCUSSION}

Attractive leg is an important secondary gender characteristic in women especially in our culture where skinny legs with bony prominences seem unattractive. Fat transfer to the extremities is a minimally invasive procedure that has unique consistency, softness, with no additional cost to patients. But the late results can be disappointing because of resorption and volume loss $[\mathbf{4 1}, \mathbf{4 4 , 4 5}]$.

Current efforts focus on minimizing resorption and providing more predictable late results. Coleman advanced "Structural Fat Grafting" technique, which focused on the atraumatic harvest method, centrifugation for purification and specific injection techniques. These steps improve fat survival hence the patient satisfaction according to coleman [4649]. In several studies the lipoaspirats was centrifuged to separate fat and to concentrates transferred adipocytes [17,18]; resulting in an increased number of viable cells per milliliter of fat transplanted [19]. It also concentrates the adipose derived mesenchymal stem cell fraction and enhance graft-take [50].

Yun Xie et al., also used a low negative pressure in aspiration of fat, with a single stage centrifugation and then they inject it into the face for cosmetic facial contouring [51]. In our study we also used low negative pressure fat aspiration and washed fat with normal saline after first centrifugation, the fat was concentrated in the middle layer then collected and a second centrifugation was done and cells from the bottom fat layer of centrifuged aspirates was used as it contains a large number of viable cells.

Studies were done to detect the effect of donor site on fat cell viability. They found no statistical differences in adipocyte viability among abdominal fat, thigh fat, flank fat or knee fat $[\mathbf{5 2 , 5 3}$. In another study by Schipper's adipocytes were found in superficial abdominal fat (superficial to Scarpa's fascia) to be the most resistant to apoptosis, and therefore a superior fat donor site [54]. Also other studies agreed on abdomen as rich source of adipocytes while medial thigh and knee to have the poorest adipocytes viability levels [55]. Also, in this study, the lower abdomen in both groups was chosen as the donor site for fat graft harvesting.

$\alpha$-granules of platelets contains: Plateletderived growth factor, transforming growth factor, platelet factor, interleukin, platelet-derived angiogenesis factor, vascular endothelial growth factor, platelet-derived endothelial growth factor, insulinlike growth factor, fibronectin which could stimulate revascularization of the implanted adipocyte- rich gel and constitute a three-dimensional matrix that allows for the arrangement of adipocytes into the correct spatial organization [56,57].

Anthony et al., stated that platelet-rich fibrinogen matrix is a better product than PRP for use in plastic surgery because: The action of PRFM is more steady and sustained for longer time, yielding increased and sustained concentrations of growth factors during healing of different wounds [42]. Several studies as Scheller have shown enhanced survival and differentiation of transplanted preadipocytes when co-injected with fibrin as a carrier material compared with controls [36].

In this study cases were divided into two groups; in group I: $100-200 \mathrm{cc}$ of fat were injected as pure fat, but in group II we choose to mix transferred fat with platelet rich fibrin matrix in ratio of 2-1 in order to get benefit of fibrin matrix together with platelet active growth factor to improve fat graft survival. We had no need to inject big amount of fat each leg had 100-200cc to minimize percent of fat necrosis.

Kakudo et al., treated human adipose-derived stem cells with activated or non-activated PRP or Platelet-Poor Plasma (PPP). They found an increase in proliferation of stem cells when treated with PRP or PPP activated with calcium and thrombin compared with that after treatment with nonactivated PRP or PPP [58].

In this study, follow-up of patients in both groups was done at 3, 6, 18 months post-operatively and in group II we injected platelet rich plasma on monthly basis for the first 6 months. This was done as out-patient clinic procedure in order to sustain providing these cases with active growth factors. This preparation was done with very minimal cost comparing this to prices of other commercial growth factors.

The average of the satisfactory results evaluated by the patients, plastic surgeons, and nurse in group I were found to be $1,0.7,1.3$. While, in group II it was more than $1.4,1.6,1.7$. This was most probably due to loss of fat injected from $28 \%$ up to $50 \%$ after 18 months of follow-up in group I.

The satisfaction ratio of surgeon in group II, could be due to longevity of the result and achievement of the aesthetic results. However, the satisfaction of the patients was determined by short term results and minimal post-operative lay-down period. This could be due to more soft texture of PRFM in comparison to fat grafts in group I. In addition, the longer average time of follow-up in group II reflect the patient satisfaction for persistent 
results and trusting in the remedy. The measurement of circumference after 18 months showed $28.5 \%$ loss.

In both groups there was no recorded infection or cellulitis as the total injected amount didn't exceed 200cc. In group II which had follow-up with injection of platelet rich plasma showed rapid improvement of discoloration and texture of skin especially in the first 3 months.

There are different causes of the soft tissue deficiency, but no matter how it becomes clear that the activated fat grafts can survive and maintained after transplantation for more than 18 months. The long-term results are even more encouraging when combined with platelet rich fibrin matrix in group II. Autologous fat grafting with activation of adipose derived mesenchymal stem cell with platelet rich fibrin matrix can be a semi-permanent option for many patients who are looking for long term cosmetic soft-tissue contouring of the leg without the need of repetition of fat graft procedure which definitely add more cost and frustration to patients.

\section{Conclusion:}

Fat graft containing adipose derived mesenchymal stem cells mixed with platelet rich fibrin matrix gave better and long lasting results with minimizing the amount of fat resorption than traditional fat injection serving both augmentation and rejuvenation purposes in a place such as lower leg with no abundant capacity and higher incidence of complications as fat resorption or cellulitis.

\section{REFERENCES}

1- Murat L. and Ercan Y.: Soft Tissue Augmentation with Autologous Fat Graft: The Dissected Pouch Technique. J. Cutan. Aesthet. Surg., Jan.-Jun., 2 (1): 21-25, 2009.

2- Chajchir A.: Fat injection: Long-term follow-up. Aesthetic Plast. Surg., 20: 291, 1996.

3- Niechajev I. and Sevcuk O.: Long-term results of fat transplantation: Clinical and histologic studies. Plast. Reconstr. Surg., 94: 496, 1994.

4- Mikus J.L., Koufman J.A. and Kilpatrick S.E.: Fate of liposuctioned and purified autologous fat injections in the canine vocal fold. Laryngoscope, 105: 17, 1995.

5- Patrick Jr. C.W.: Tissue-engineering strategies for adipose tissue repair. Anat. Rec., 263 (4): 361-6, 2001.

6- Patrick Jr. C.W.: Adipose tissue engineering: The future of breast and soft tissue reconstruction following tumor resection. Semin. Surg. Oncol., 19 (3): 302-11, 2000.

7- Patrick C.W.: Breast tissue engineering. Annu. Rev. Biomed. Eng., 6: 109-30, 2004.

8- Patrick C.W., Mikos A.G. and McIntire L.V.: Frontiers in tissue engineering, $1^{\text {st }}$ ed. Oxford, UK and New York: Pergamon, 1998.
9- Chan C.W., McCulley S.J. and Macmillan R.D.: Autologous fat transfer e a review of the literature with a focus on breast cancer surgeryJournal of Plastic, Reconstructive \& Aesthetic Surgery, 61, 1438, 2008.

10- Carpaneda C.A.: Study of aspirated adipose tissue. Aesthetic Plast. Surg., 20: 399, 1996.

11- Chajchir A. and Benzaquen I.: Fat-grafting injection for soft-tissue augmentation. Plast. Reconstr. Surg., 84: 921, 1989.

12- Lewis C.M.: The current status of autologous fat grafting. Aesthetic. Plast. Surg., 17: 109, 1993.

13- Niechajev I. and Sevcuk O.: Long-term results of fat transplantation: Clinical and histologic studies. Plast. Reconstr. Surg., 94: 496, 1994.

14- Boschert M.T., Beckert B.W., Puckett C.L., et al.: Analysis of lipocyte viability after liposuction. Plast. Reconstr. Surg., 109: 761, 2002.

15- Rigotti G., Marchi A., Galie M., et al.: Clinical treatment of radiotherapy tissue damage by lipoaspirate transplant: A healing process mediated by adipose-derived adult stem cells. Plast. Reconstr. Surg., 119: 1409, 2007.

16- Yoshimura K., Sato K., Aoi N., Kurita M., Hirohi T. and Harii K.: Cell assisted lipotransfer for cosmetic breast augmentation: Supportive use of adipose derived stem/ stromal cells. Aethet. Plast. Surg., 32: 48, 2008.

17- Moseley T.A., Zhu M. and Hedrick M.H.: Adipose-derived stem and progenitor cells as fillers in plastic and reconstructive surgery. Plast. Reconstr. Surg., 118: 121, 2006.

18- Butterwick K.J.: Lipoaugmentation for aging hands: A comparison of the longevity and aesthetic results of centrifuged versus noncentrifuged fat. Dermatol. Surg., 28: 987, 2002.

19- Shiffman M.A. and Mirrafati S.: Fat transfer techniques: The effect of harvest and transfer methods on adipocyte viability and review of the literature. Dermatol. Surg., 27: 819, 2001.

20- Marx R.E., Carlson E.R., Eichataedt R.M., et al.: Platelet rich plasma: Growth factor enhancement for bone graft. J. Oral Maxillofac. Surg., 51: 1181-93, 1993.

21- Marx R.E.: Platelet-rich plasma (PRP): What is PRP and what is not PRP? Implant. Dent., 10: 225-228, 2001.

22- Mazzucco L., Medici D., Serra M., et al.: The use of autologous platelet gel to treat difficult-to-heal wounds: A pilot study. Transfusion, 44: 1013-1018, 2004.

23- Eppley B.L., Siders R.A., Platis J.M., et al.: Bioactivation of free-fat transfers: A potential new approach to improving graft survival. Plast. Reconstr. Surg., 90: 1022-1030, 1992.

24- Eppley B.L., Snyders R.V., Winkelmann T., et al.: Autologous facial fat transplantation: Improved graft maintenance by microbead bioactivation. J. Oral Maxillofac. Surg., 50: 477-482, 1992.

25- Eppley B.L. and Sadove A.M.: A physicochemical approach to improving free fat survival: Preliminary observations. Aesthetic Plast. Surg., 15: 215-218, 1991.

26- Yuksel E., Weinfeld A.B., Cleek R., et al.: Increased free fat-graft survival with the long-term, local delivery of insulin, insulin-like growth factor-I, and basic fibroblast 
growth factor by PLGA/PEG microspheres. Plast. Reconstr. Surg., 105: 1712-1720, 2000.

27- Abuzeni P.Z. and Alexander R.W.: Enhancement of autologous fat transplantation with platelet rich plasma. Am. J. Cosm. Surg., 18: 59-70, 2001.

28- Man D., Plosker H. and Winland-Brown J.E.: The use of autologous platelet-rich plasma (platelet gel) and autologous platelet-poor plasma (fibrin glue) in cosmetic surgery. Plast. Reconstr. Surg., 107: 229-239, 2001.

29- Powell D.M., Chang E. and Farrior E.H.: Recovery from deep-plane rhytidectomy following unilateral wound treatment with autologous platelet gel. Arch. Facial Plant. Surg., 3: 245-250, 2001.

30- Kassolis J.D. and Reynolds M.A.: Evaluation of the adjunctive benefits of platelet rich plasma in subantral sinus segmentation. J. Craniofac. Surg., 16: 280-287, 2005.

31- Sadati K.S., Corrado A.C. and Alexander R.W.: Plateletrich plasma (PRP) utilized to promote greater graft volume retention in autologous fat grafting. Am. J. Cosm. Surg., 23: 203-211, 2006.

32- Anitua E., Sanchez M., Nurden A.T., et al.: Autologous fibrin matrices: A potential source of biological mediators that modulate tendon cell activities. J. Biomed. Mater Res. A, 77 (2): 285-93, 2006.

33- Farrell D.H. and Al-Mondhiry H.A.: Human fibroblast adhesion to fibrinogen. Biochemistry, 36 (5): 1123-8, 1997.

34- Sahni A., Odrljin T. and Francis C.W.: Binding of basic fibroblast growth factor to fibrinogen and fibrin. J. Biol. Chem., 273 (13): 7554, 1998.

35- Torio-Padron N., Baerlecken N., Momeni A., et al.: Engineering of adipose tissue by injection of human preadipocytes in fibrin. Aesthetic Plast. Surg., 31 (3): 285-93, 2007.

36- Schoeller T., Lille S., Wechselberger G., et al.: Histomorphologic and volumetric analysis of implanted autologous preadipocyte cultures suspended in fibrin glue: A potential new source for tissue augmentation. Aesthetic Plast. Surg., 25 (1): 57-63, 2001.

37- Azzena B., Mazzoleni F., Abatangelo G., et al.: Autologous platelet-rich plasma as an adipocyte in vivo delivery system: Case report. Aesthetic Plast. Surg., 32 (1): 1558.

38- Cervelli V. and Gentile P.: Use of platelet gel in Romberg syndrome. Plast. Reconstr. Surg., 123 (1): 22e-3e, 2009.

39- Nitche J., Greco S., Merriam A., et al.: Platelet rich fibrin matrix to enhance periarticular tendon to bone healing. Presented at: The American Orthopedic Society for Sports Medicine Annual Meeting. Orlando, July 10-13, 2008.

40- Sa Nchez M., Anitua E., Azorfa J., et al.: Comparison of surgically repaired Achilles tendon tears using platelet rich fibrin matrices. Am. J. Sports Med., 35 (2): 245-51, 2007.

41- Coleman S.R.: Structural fat grafting: More than a permanent filler. Plast. Reconstr. Surg., 118 (3 Suppl): 108, 2006.

42- Anthony P. Sclafani, M.D.a,b,* and Masoud Saman, M.D.c: Platelet-Rich Fibrin Matrix for Facial Plastic
Surgery Facial Plast. Surg. Clin. N. Am., 20: 177-186, 2012.

43- Sonnleitner D., Huemer P. and Sullivan D.Y.: A simplified technique for producing platelet-rich plasma and platelet concentrate for intraoral bone grafting techniques: A technical note. Int. J. Oral Maxillofac. Implants., 15: 87982, 2000.

44- Patrick Jr. C.W.: Tissue-engineering strategies for adipose tissue repair. Anat. Rec., 263 (4): 361-6, 2001.

45- Patrick Jr. C.W.: Adipose tissue engineering: The future of breast and soft tissue reconstruction following tumor resection. Semin. Surg. Oncol., 19 (3): 302-11, 2000.

46- Coleman S.R.: Facial recontouring with lipostructure. Clin. Plast. Surg., 24: 347, 1997.

47- Coleman S.R.: Long-term survival of fat transplants: Controlled demonstrations. Aesthetic Plast. Surg., 19: $421,1995$.

48- Coleman S.R.: $3^{\text {rd }}$ WP. Fat transplantation. Dermatol. Clin., 17: 891, 1999.

49- Coleman S.R.: $3^{\text {rd }}$ WP. Autologous fat transplantation. Plast. Reconstr. Surg., 88: 736, 1991.

50- Kurita M., Matsumoto D., Shigeura T., et al.: Influences of centrifugation on cells and tissues in liposuction aspirates: Optimized centrifugation for lipotransfer and cell isolation. Plast. Reconstr. Surg., 121: 1033, 2008.

51- Yun Xie, Dan Ning Zheng, Qing Feng Li, Bin Gu, Kai Liu, Guo Xiong Shen and Lee L.Q. Pu: An integrated fat grafting technique for cosmetic facial contouring. Journal of Plastic, Reconstructive \& Aesthetic Surgery, 63, 270, 2010.

52- Rohrich R., Sorokin E. and Brown S.: In search of improved fat transfer viability: A quantitative analysis of the role of centrifugation and harvest site. Plast. Reconstr. Surg., 113: 392-395, 2004.

53- Suga H., Matsumoto D., Inoue K., Shigeura T., Eto H., Aoi N., et al.: Numerical measurement of viable and nonviable adipocytes and other cellular components in aspirated fat tissue. Plast. Reconstr. Surg., 122: 103-114, 2008.

54- Schipper B.M., Marra K., Zhang W., Donnenberg A.D. and Rubin J.P.: Regional anatomic and age effects on cell function of adipose-derived stem cells. Ann. Plast. Surg., 60: 538-544, 2008.

55- Padoin A.V., Braga-Silva J., Martins P., Rezende K., Rezende A.R., Grechi B., et al.: Sources of processed lipoaspirate cells: influence of donor site on cell concentration. Plast. Reconstr. Surg., 122: 614-618, 2008.

56- Bruno Azzena, Francesco Mazzoleni, Giovanni Abatangelo, Barbara Zavan and Vincenzo Vindigni: Autologous Platelet-Rich Plasma as an Adipocyte In Vivo Delivery System: Case Report Aesth. Plast. Surg., 32: 155-158, 2008.

57- Eppley B.L., Pietrzak W.S. and Blanton M.: Platelet-rich plasma: A review of biology and applications in plastic surgery. Plast. Reconstr. Surg., 118: 147e-159, 2006.

58- Kakudo N., Minakata T., Mitsui T., Kushida S., Notodihardjo F.Z. and Kusumoto K.: Proliferation-promoting effect of plateletrich plasma on human adipose-derived stem cells and human dermal fibroblasts. Plast. Reconstr. Surg., 122: 1352-1360, 2008. 